\title{
Erratum to "Hypothesis of Primary Particles and the Creation of the Big Bang and Other Universes" [Journal of Modern Physics Volume 10 (2019) 1532-1547]
}

\author{
Slobodan Spremo \\ Mathematical Grammar School, Belgrade, Serbia \\ Email: slobodan.spremo@gmail.com
}

Received: October 14, 2019

Accepted: November 17, 2019

Published: November 20, 2019

Copyright $\odot 2020$ by author(s) and Scientific Research Publishing Inc. This work is licensed under the Creative Commons Attribution International License (CC BY 4.0).

http://creativecommons.org/licenses/by/4.0/
The original online version of this article (Slobodan, S. (2019) Hypothesis of Primary Particles and the Creation of the Big Bang and Other Universes. Journal of Modern Physics, 10, 1532-1547. https://doi.org/10.4236/jmp.2019.1013102) unfortunately contains two mistakes.

1) Equation (13) contains an error, so it has to be replaced by this equation.

$$
x^{\prime}=C^{2}\left(x^{\prime}+c t^{\prime}-c t^{\prime}-\frac{c^{2}}{u^{2}} x^{\prime}\right)
$$

2) The Sections 6 and 7 should not be read because the way of calculation in them is not in accordance to the third postulate. These sections do not affect the results stated in the article. 